\title{
Association of acepromazine with propofol in giant amazon turtles Podocnemis expansa reared in captivity ${ }^{1}$
}

\author{
Associação da acepromazina com propofol em tartarugas-da-amazônia \\ Podocnemis expansa criadas em cativeiro
}

\begin{abstract}
José Roberto Ferreira Alves-Júnior ${ }^{\mathrm{I}}$, Andréa Cristina Scarpa Bosso"II, Mariana Batista Andrade ${ }^{\mathrm{II}}$, Valéria de Sá Jayme ${ }^{\mathrm{III}}$, Karin Werther $^{\mathrm{IV}}$, André Luiz Quagliatto Santos ${ }^{\mathrm{V}}$

${ }^{\mathrm{I}}$ Master, Veterinarian, Veterinary Sciences, UFU, Uberlandia-MG, Brazil. Conception, design, acquisition, interpretation of the data, drafting and revising of the article; anaesthesia procedures.

IIMaster, Veterinarian, Veterinary Sciences, UFU, Uberlandia-MG, Brazil. Acquisition of data, anaesthesia procedures, critical revision,

IIIAssociate Professor, Preventive Veterinary Medicine, Goias Federal University (UFG), Brazil. Interpretation of data and critical revision.

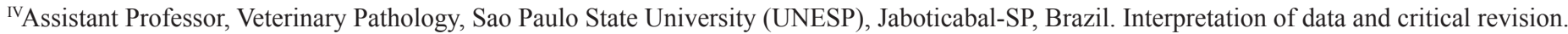

vFull Professor, Animal Anatomy, Wild Animals Research Laboratory, UFU, Uberlandia-MG, Brazil. Conception, design, data acquisition and interpretation of data; anaesthesia procedures; critical revision.
\end{abstract}

\begin{abstract}
PURPOSE: To evaluate the effects of different concentrations of an anesthetic association in giant amazon turtles (Podocnemis expansa). METHODS: Twenty healthy P. expansa of both sexes weighing between 1.0 and $1.5 \mathrm{~kg}$ commercially bred in the Araguaia River Valley, Goias, Brazil, were separated into two groups ( $\mathrm{G} 1 \mathrm{n}=10$ and $\mathrm{G} 2 \mathrm{n}=10)$. Each group received a respective protocol: $\mathrm{P} 1=$ acepromazine $(0.5 \mathrm{mg} / \mathrm{kg} \mathrm{IM})$ and propofol $(5 \mathrm{mg} / \mathrm{kg} \mathrm{IV})$ and P2 = acepromazine $(0.5 \mathrm{mg} / \mathrm{kg} \mathrm{IM})$ and propofol $(10 \mathrm{mg} / \mathrm{kg} \mathrm{IV})$. The acepromazine was administered in the left thoracic member and the propofol in the cervical vertebral sinus. Assessments were made of the anesthetic parameters of locomotion, muscle relaxation, response to pain stimuli in the right thoracic and pelvic members and heartbeat.

RESULTS: The anesthetic induction time was the same for both protocols (P1 and P2); however the P2 effects were of a longer duration. CONCLUSION: The sedation achieved with both protocols (P1 and P2) were satisfactory for the biological sample collection, physical examinations and minor surgeries on this species.
\end{abstract}

Key words: Anesthesia. Acepromazine. Propofol. Reptiles. Turtles.

\section{RESUMO}

OBJETIVO: Avaliar os efeitos de uma associação anestésica com diferentes concentrações em tartarugas-da-amazônia (Podocnemis expansa).

MÉTODOS: Vinte P. expansa, hígidas, de ambos os sexos, com massa corporal entre 1,0 e 1,5 kg, de um criatório comercial localizado no vale do rio Araguaia, Goiás, Brasil, foram distribuídas em dois grupos ( $\mathrm{G} 1 \mathrm{n}=10$ e G2 n=10). Cada grupo recebeu um protocolo sendo: P1 = acepromazina (0,5 mg/kg IM) e propofol (5 mg/kg IV) e P2 = acepromazina (0,5 mg/kg IM) e propofol (10 mg/kg IV), aplicados nos grupos G1 e G2, respectivamente. A acepromazina foi aplicada no membro torácico esquerdo e o propofol no seio vertebral cervical. Foram avaliados os parâmetros anestésicos: locomoção, relaxamento muscular, resposta aos estímulos dolorosos no membro torácico direito e nos membros pelvinos e frequência cardíaca.

RESULTADOS: O tempo de indução anestésica foi o mesmo para ambos os protocolos (P1 e P2), porém o P2 apresentou efeitos mais duradouros.

CONCLUSÃO: As sedações obtidas por esses protocolos (P1 e P2) foram satisfatórias para a colheita de amostras biológicas, exames físicos e realização de pequenos procedimentos cirúrgicos nesta espécie.

Descritores: Anestesia. Acepromazina. Propofol. Répteis. Tartarugas. 


\section{Introduction}

During the 1970s and 80s, hypothermia and ether inhalation were the immobilization and anesthesia techniques most used in reptile medicine, but there were high risks and results were sometimes ineffective. Presently, pharmacologic contention and anesthesia are the routine procedures for physical and clinical examinations and surgeries ${ }^{1}$.

Propofol as a drug was first used as an inhalation anesthesia in tortoises Gopherus polyphemus ${ }^{2}$. Its effect was studied when associated with ketamine as a surgical anesthetic for Trachemys scripta ${ }^{3}$ and $P$. expansa ${ }^{4}$. In the same species Santos et al. ${ }^{5}$ studied the combination of propofol and xylazine in pharmacological contention.

According to Heard ${ }^{6}$ the use of injectable anesthetics has been increasing in veterinary medicine for reptiles. Additionally, propofol is a drug characterized by fast induction and recovery. The substance is a fat-soluble hypnotic, decreasing the systemic arterial pressure and the heart debt in mammals with minimal alteration to the heart beat ${ }^{7}$ and with no detectable arrhythmias ${ }^{8}$.

Phenothiazines are frequently used in the anesthesia routine because of its sedative effect and also for potentiating the barbiturate, non barbiturate and dissociative anesthetic agents. In addition they have sympatholytic, anxiolytic and antispasmodic sedative effects 9 . Among the phenothiazines, the acepromazine is most featured in veterinary medicine $\mathrm{e}^{10}$.

The objective of this work was to evaluate the effects of the anesthetic combination of acepromazine $0.5 \mathrm{mg} / \mathrm{kg}$ IM with propofol $5 \mathrm{mg} / \mathrm{kg} \mathrm{IV}$ and acepromazine $0.5 \mathrm{mg} / \mathrm{kg} \mathrm{IM}$ with propofol $10 \mathrm{mg} / \mathrm{kg} \mathrm{IV}$ in $P$. expansa.

\section{Methods}

The experiment took place at a commercial breeder $\left(15^{\circ} 04^{\prime} 18^{\prime \prime} \mathrm{S}\right.$ and $50^{\circ} 25^{\prime} 2.4^{\prime \prime} \mathrm{W}-340 \mathrm{~m}$ altitude) localized in the Araguaia River Valley, Goias, Brazil. All procedures and freshwater turtle evaluations were conducted in medium air temperature of $31.9 \pm 2.1^{\circ} \mathrm{C}$ measured with a thermometer showing maximum and minimum temperatures.

Twenty healthy, about three-year-old $P$. expansa of both sexes with body mass between 1.0 and $1.5 \mathrm{~kg}$ were taken from their breeding tanks using nets and were weighed and identified individually. The animals were distributed into two groups (G1 and G2) each with ten animals and given no liquids for 12 hours and given no food for 24 hours prior to being submitted to anesthetic protocols.
The G1 group received the anesthetic protocol P1 (acepromazine $0.5 \mathrm{mg} / \mathrm{kg} \mathrm{IM}$ and propofol $5.0 \mathrm{mg} / \mathrm{kg} \mathrm{IV}$ ) and the G2 group received the anesthetic protocol P2 (acepromazine $0.5 \mathrm{mg} / \mathrm{kg}$ IM and propofol $10.0 \mathrm{mg} / \mathrm{kg}$ IV). The acepromazine was administered intramuscular in the left thoracic member and 15 minutes later the propofol was applied intravenously in the cervical vertebral sinus. Both injections were realized after local antisepsis.

The anesthetic parameters were measured at $0,5,10$, $20,30,45,60,90,120,150$ and 180 minutes after application of the drugs. Time zero was the moment when propofol was administered, fifteen minutes after acepromazine administration. Subjective scores of one (1) for minimal effects, two (2) for intermediary effects, and three (3) for maximum effects were used for the parameters described below:

1. Locomotion: (1) animal with normal ability to move, (2) difficulty with movement, and (3) absence of movement.

2. Muscle relaxation: (1) the animal kept its head up or retracted, (2) an intermediary situation, and (3) the head, members and tail remained relaxed.

For the sensibility pain test of the right thoracic member and both pelvic members, a pair of $16 \mathrm{~cm}$ hemostatic Kelly pincers was applied on the second lock in the phalanges of the fore and hind limbs respectively. If the animal responded to the pain stimulus it received a score of zero (0). If there was no response a score of one (1) was recorded.

The heartbeat was measured using a vascular Doppler at $0,10,30,60,120$ and 180 minutes after applying the second drug.

The nonparametric Mann-Whitney $U$ test (with the level of significance set at 0.05 ) was used to check for significant differences in recorded values.

\section{Results}

Groups G1 and G2 did not present a statistically significant difference in the parameter of pain sensitivity in the right thoracic member at the different times $(\mathrm{p}>0.05)$. However, statistically significant differences were recorded for the pain sensitivity parameter in the pelvic members at 5, 10, 20, 30, 45, 90, 120, 150 and 180 minutes; locomotion at 120,150 and 180 minutes; muscle relaxation at 30,120,150 and 180 minutes and heartbeat at 60, 120 and 180 minutes, as indicated in figures 1, 2, 3 and 4 respectively (Figure 1). 


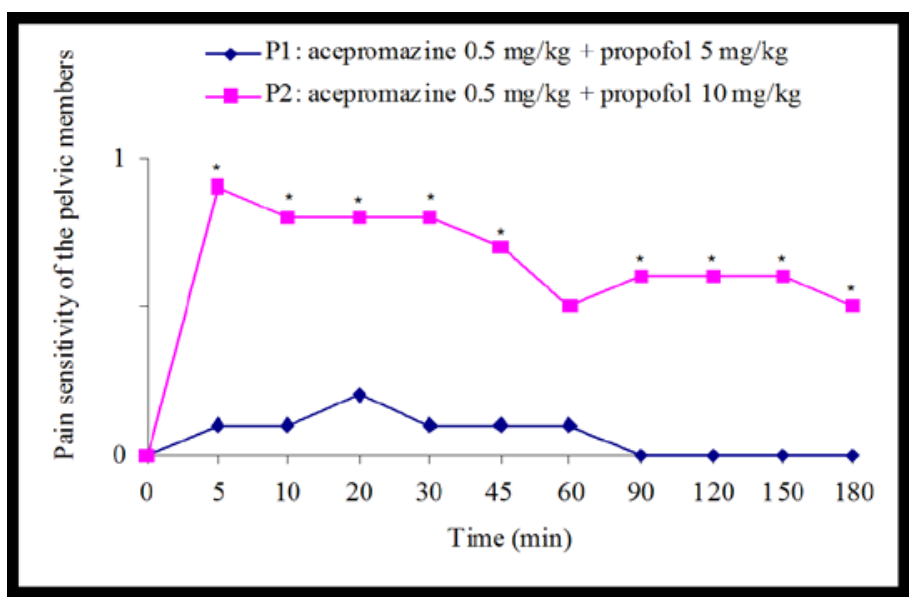

FIGURE 1 - Average scores of pain sensitivity of the pelvic members at different times in $P$. expansa (G1 and G2) submitted to different anesthetic protocols ( $\mathrm{P} 1$ and $\mathrm{P} 2)$. The asterisks indicate significant differences between the groups $(\mathrm{p}<0.05)$.

The group receiving anesthetic protocol $\mathrm{P} 1$ demonstrated a zero (0) score in all the animals (10) for pain sensitivity in the pelvic members at 5, 10, 30, 45 and 60 minutes, while the group receiving the $\mathrm{P} 2$ protocol had only one animal at 5 minutes and two freshwater turtles at 10,20 and 30 minutes presenting a zero (0) score for the same parameter. At 90 minutes, all animals from G1 presented a zero (0) score for the pain parameter when stimulated by pinching in the pelvic members. The G2 group presented the same score after 180 minutes (Figure 2).

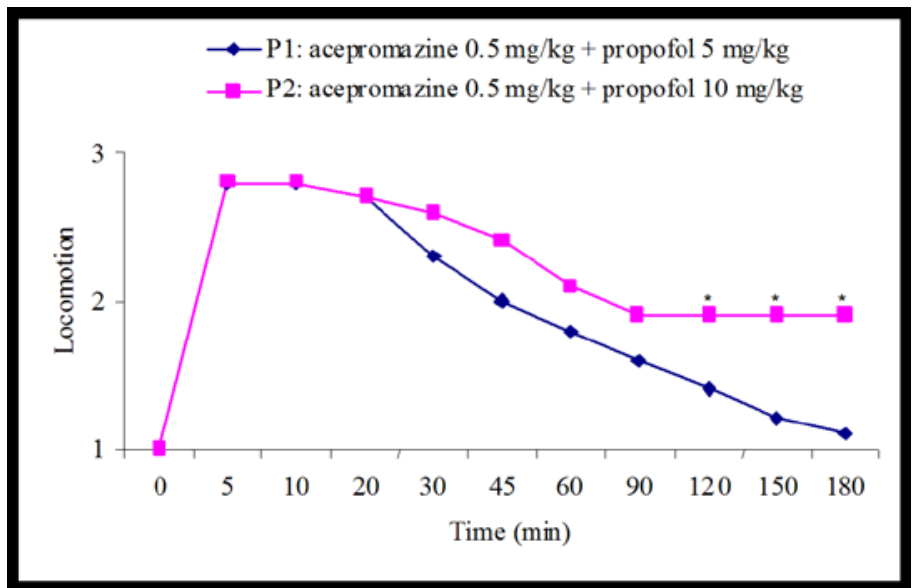

FIGURE 2 - Average scores for locomotion at different times in $P$. expansa (G1 and G2) submitted to different anesthetic protocols (P1 and $\mathrm{P} 2)$. The asterisks indicate significant differences between the groups $(\mathrm{p}<0.05)$.

After 120 minutes, seven specimens from G1 presented no problems with movement; however, in G2 only three animals were able to move. The others animals from both groups presented a score of two (2) for this parameter (Figure 3).

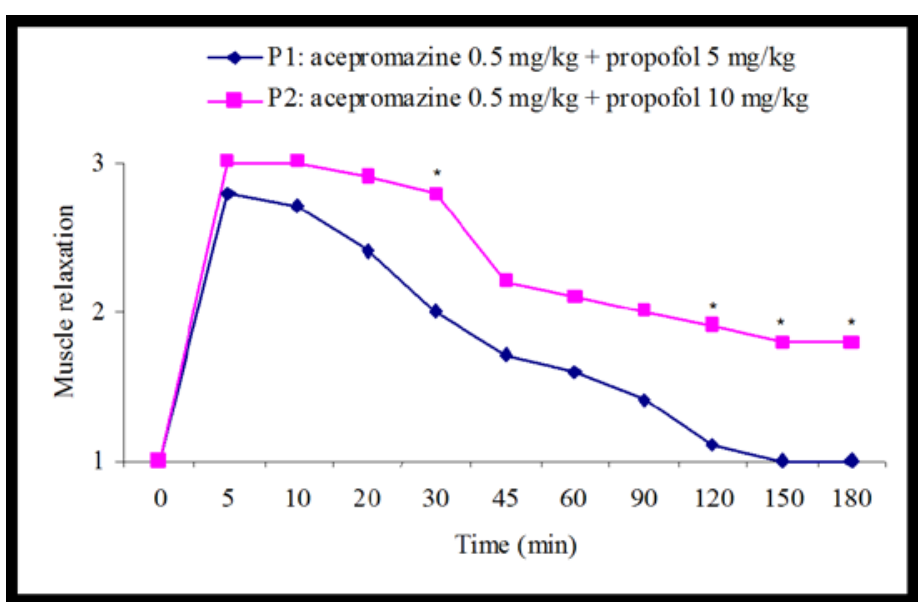

FIGURE 3 - Average scores for muscle relaxation at different times in P. expansa (G1 and G2) submitted to different anesthetic protocols (P1 and $\mathrm{P} 2$ ). The asterisks indicate significant differences between the groups $(\mathrm{p}<0.05)$.

Five minutes after the propofol was administered all the testudines from G2 presented a score of three (3) for muscle relaxation, while nine from G1 obtained this score. One of the animals submitted to protocol P1 scored two (2) as its maximum score (Figure 4).

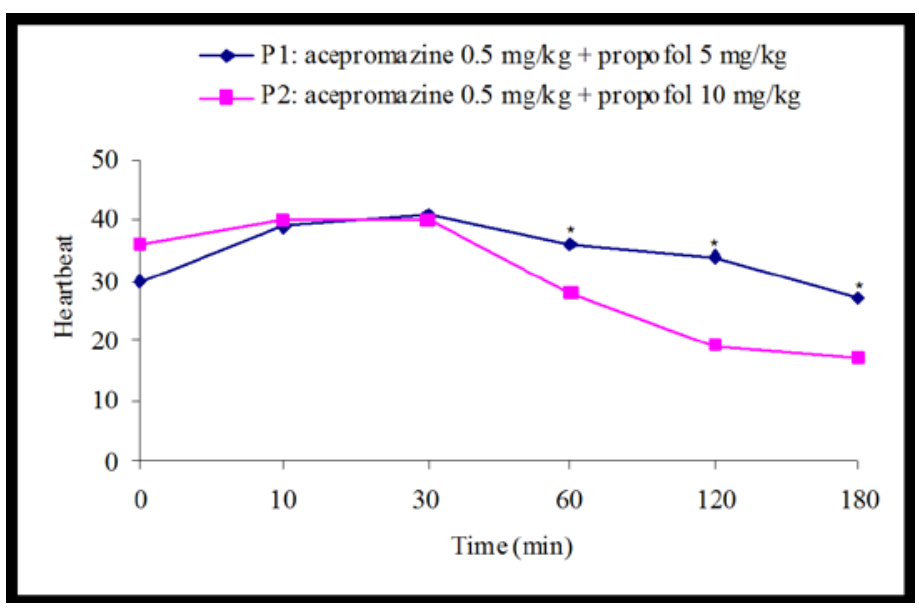

FIGURE 4 - Heartbeat average at different times in $P$. expansa (G1 and $\mathrm{G} 2)$ submitted to different anesthetic protocols (P1 and P2). The asterisks indicate significant differences between the groups $(\mathrm{p}<0.05)$.

The freshwater turtles from G2 presented significant bradycardia $(\mathrm{p}<0.05)$ when compared to $\mathrm{G} 1$ at 60,120 and 180 minutes. Until one hour after the application of propofol, statistically significant differences between the two groups were not observed.

The time for anesthetic induction was the same for both protocols (P1 and P2); however, the effects lasted longer for the freshwater turtles from G2.

None of the reptiles studied presented collateral effects 
or died due to the application of the drugs.

\section{Discussion}

Air temperatures when running the protocols (P1 and P2) were optimal because according to Bennett ${ }^{1}$, the reptile's metabolism is best suited when the air temperature is between 28 and $36^{\circ} \mathrm{C}$.

The use of acepromazine as a prior anesthetic drug promoted adequate sedation. The animals became unable to move and presented no response to handling or to the propofol administration. These detections conform to Meyer ${ }^{10}$, who described a good sedative action for this drug.

Pye and Carpenter $^{3}$ claim the propofol presents hypotension and apnea as colateral effects. Sebbel and Lowdon ${ }^{11}$ observed the propofol injection in "bolus" resulted in high levels of apnea during the induction. According to Bennett ${ }^{1}$ the reptiles can withstand periods of apnea by breeding anaerobically. Santos et $a l .{ }^{4}$, when using the combination of propofol and ketamine in two different dosages in P. expansa observed the two groups evaluated presented apnea, but they didn't receive mechanical ventilation resulting in cyanosis in the oral mucosa. In the present study, apnea was not observed in the testudines because to avoid this problem we spread the application of the propofol doses over a 1 minute period, as demonstrated by Mama ${ }^{12}$ in felines. To prevent the hypoxia and hypercarpnia, Heard ${ }^{6}$ recommends the intubation of the testudines and mechanical ventilation.

The G1 group presented average scores of pain sensitivity in the pelvic members $(\mathrm{p}<0.05)$, significantly lower than G2 in almost all the measured times except at 60 minutes. In other words, most of the animals from G1 presented pain when stimulated by pinching (Figure 1). Magella and Cheibub ${ }^{13}$ reported an increase in the analgesia of the propofol when the dose is increased. Thus, the acepromazine didn't interfere in the analgesia of the tested groups since according to Mosley ${ }^{14}$ these phenothiazines tend to create ineffective sedation in reptiles, making it necessary to use higher dosages of this drug. According to Nunes et al. ${ }^{9}$, the acepromazine only tranquilizes and potentiates the barbiturate, non barbiturates and dissociative anesthetics, but doesn't cause analgesia.

According to Short and Bufalari ${ }^{7}$, the propofol induction and recovery time is fast and varies with the doses applied. Maclean et al. ${ }^{15}$, when using $5 \mathrm{mg} / \mathrm{kg}$ of propofol in testudines of the species Caretta caretta observed fast induction and recovery while providing enough sedation of the animals for short periods of surgical anesthesia. In this study, no significant difference ( $p>0.05$ ) between the groups G1 and G2 at the measured times of 0 to 90 minutes was observed, but beginning at 120 minutes, the turtles from G1 had significantly $(\mathrm{p}<0.05)$ lower scores for locomotion when compared to G2 (Figure 2). This is compatible with Short and Bufalari's ${ }^{7}$ observation: the bigger the doses applied, the longer the time to recover.

No significant differences $(\mathrm{p}>0.05)$ were observed in the average scores for muscle relaxation at $0,5,10,20,45,60$ and 90 minutes; however, at 30,120, 150 and 180 minutes there were significant differences $(\mathrm{p}<0.05)$ between the groups with $\mathrm{G} 1$ presenting lower average scores for the muscle relaxation parameter (Figure 3). Five minutes after the propofol administration, all the testudines from G2 presented level (3) as the maximum score for muscle relaxation, while nine from G1 obtained the same score. Thus, as observed by Magella and Cheibub ${ }^{13}$, the propofol effects are dose-dependent, or in other words, directly proportional to the doses. According to Duke ${ }^{16}$, muscle relaxation is one of the most important characteristics of this injectable anesthetic.

The turtles from G2 presented significant bradycardia $(p<0.05)$ when compared with those from G1 (Figure 4) at 60, 120 and 180 minutes. This reaction might not be caused by acepromazine, even though the drug is known for causing arterial hypotension, since the dose was the same in both groups. In all probability, the higher doses of propofol $(10 \mathrm{mg} /$ $\mathrm{kg}$ IV) administered in the G2 group directly interfered with the heart rate decrease in these animals as reported by Magella and Cheibub $^{13}$ and Heard ${ }^{6}$. Beyond being an important cardiovascular system depressor, the higher the dose, the bigger the influence in depressing heart activity.

Goodchild and Serrao ${ }^{17}$ described the use of high dosages of propofol in dogs as the originator of alterations in heartbeat due to the direct action of the drug in all the venomotor autonomic nervous system nerves and on the control of the arterial vascular tone. However, Keegan and Greene ${ }^{18}$ concluded that propofol did not cause any cardiorespiratory alteration in dogs when anesthetized with continuous infusion. Such findings are important for future research using continuous infusion of the anesthetic in testudines, but Bennett et al. ${ }^{19}$ warns of the difficulty in the catheterization of young and small reptiles. The author also recommends intubation and the use of artificial ventilation after administering propofol to prevent hypoxia and hypercarpnia.

\section{Conclusions}

The associations P1 (acepromazine $0.5 \mathrm{mg} / \mathrm{kg} \mathrm{IM}$ and propofol $5.0 \mathrm{mg} / \mathrm{kg} \mathrm{IV}$ ) and P2 (acepromazine $0.5 \mathrm{mg} / \mathrm{kg}$ IM and propofol $10.0 \mathrm{mg} / \mathrm{kg} \mathrm{IV}$ ) were not effective as surgical anesthesia in 
P. expansa. However, for sedation both were satisfactory, enabling pharmacological contention, biological sample collection, physical exams and conducting painless procedures in this species.

\section{References}

1. Bennett RA. A review of anesthesia and chemical restraint in reptiles. J Zoo Wildl Med. 1991;22(3):282-303.

2. Dennis PM, Heard DJ. Cardiopulmonary effects of a medetomidineketamine combination administered intravenously in gopher tortoises. J Am Vet Med Assoc. 2002;220(10):1516-9.

3. Pye GW, Carpenter JW. Ketamine sedation followed by propofol anesthesia in a slider, Trachemys scripta, to facilitate removal of an esophageal foreign body. Bull Assoc Rept Amph Vet. 1998;8(1):167.

4. Santos ALQ, Magalhães LM, Lima CAP, Nascimento LR, Menezes LT, Kaminishi APS, Alves Júnior JRF, Ávila Júnior RH. Anestesia de tartaruga-da-amazônia Podocnemis expansa (Schweigger, 1812)-Testudines, Podocnemididae, com a associação cetamina e propofol. Pubvet. 2011;5(19):1-11.

5. Santos ALQ, Bosso ACS, Alves Júnior JRF, Brito FMM, Pachally JR, Ávila Júnior RH. Pharmacological restraint of captivity giant Amazonian turtle Podocnemis expansa (Testudines, Podocnemididae) with xylazine and propofol. Acta Cir Bras. 2008;23(3):270-3.

6. Heard DJ. Reptile anesthesia. Vet Clin North Am Exot Anim Pract. 2001;4(1):83-117.

7. Short CE, Bufalari A. Propofol anesthesia. Vet Clin North Am Small Anim Pract. 1999;29(3):747-78.

8. Quandt JE, Robinson EP, Rivers WJ, Raffe MR. Cardiorespiratory and anesthetic effects of propofol and thiopental in dogs. Am J Vet Res. 1998;59(9):1137-43.

9. Nunes N, Massone F, Pompermayer LG, Pirolo J. Estudo da atividade antiarritmogênica da levomepromazina em cães submetidos à anestesia pela quetamina. Cienc Rural. 1999;29(2):291-5.

10. Meyer EK. Rare, idiosyncratic reaction to acepromazine in dogs. J Am Vet Med Assoc. 1997;210(8):1114-5.

11. Sebbel PS, Lowdon JD. Propofol: a new intravenous anesthetic. Anesthesiology. 1989;71(1):260-77.

12. Mama K. New drugs in feline anesthesia. Comp Cont Educ Pract Vet. 1998;20(2):125-39.

13. Magella HA, Cheibub ZB. Propofol: revisão bibliográfica. Rev Bras Anestesiol. 1990;40(4):289-94.

14. Mosley CAE. Anesthesia and analgesia in reptiles. Sem Avian Exotic Pet Med. 2005;14(4):243-62.

15. Maclean RA, Harms C, Braun-Mcneill J. Propofol anesthesia in loggerhead (Caretta caretta) sea turtle. J Wildl Dis. 2008;44(1):14350 .

16. Duke T. A new intravenous anesthetic agent: propofol. Can Vet J. 1995;36(3):181-3.

17. Goodchild CS, Serrao JM. Cardiovascular effects of propofol in the anaesthetized dog. Br J Anesth. 1989;63(1):87-92.

18. Keegan RD, Greene SA. Cardiovascular effects of a continuous two hour propofol infusion in dogs comparison with isoflurane anesthesia. Vet Surg. 1993;22(6):537-43.

19. Bennett RA, Schumacher J, Hedjazi-Haring K, Newlel SM. Cardiopulmonary and anaesthetic effect of propofol administered intraosseously to green iguanas. J Am Vet Med Assoc. 1998;212(1):93-8.

\section{Correspondence:}

André Luiz Quagliatto Santos ${ }^{\mathrm{VI}}$

Universidade Federal de Uberlândia

Laboratório de Ensino e Pesquisa em Animais Silvestres

Avenida Pará, 1720, Campus Umuarama, Bloco T

38400-902 Uberlândia - MG Brasil

Tel.: (55 34)3218-2696

quagliatto@famev.ufu.br

Received: March 20, 2012

Review: May 21, 2012

Accepted: June 18, 2012

Conflict of interest: none

Financial source: none

${ }^{1}$ Research performed at Wild Animals Research Laboratory, Federal University of Uberlandia (UFU), Minas Gerais, Brazil. 